\title{
THE IMMIGRATION EXPERIENCE OF LATIN AMERICAN FAMILIES: RESEARCH AND ACTION ON PERCEIVED RISK AND PROTECTIVE FACTORS
}

\author{
ISAAC PRILLELTENSKY \\ Wilfrid Laurier University
}

\begin{abstract}
The purpose of this paper is twofold. First, to contribute to the understanding of risk and protective factors involved in the adaptation of immigrants and refugees. Second, to report on a collaborative, community-driven, actionresearch project. Both goals were incorporated into a conceptual framework aimed at integrating general knowledge on the topic with the unique experiences of a group of refugees, for the purpose of generating action. The study began addressing three weaknesses of the literature: (a) the lack of investigations on the adaptation of immigrant and refugee children, (b) the need to explore protective mechanisms within refugee families, and (c) the paucity of unity between research and practice.
\end{abstract}

This article is based on action research with a Latin American community residing in a city in southern Ontario. The purpose of the paper is twofold. First, to contribute to the literature on risk and protective factors experienced by immigrant and refugee children and adults. Second, to report a case study of communitydriven research which served to catalyze action to reduce stress and promote better coping among immigrants.

With respect to the first goal, research disproportionally reflects the immigration and refugee experience of adults at the expense of investigations examining the adaptation process of children. As Beiser et al, recently put it in their federal report on mental health issues affecting immigrants and refugees, "research to establish the extent of mental health need and the conditions creating mental health risk among migrant children and youth is much needed" (1988, p. 71). The present study makes a step in the direction suggested by Beiser and his colleagues.

A second limitation found in the literature pertains to its excessive focus on risk factors (Grant, 1983). Risk and protective factors may be conceptualized as circumstances, events, or characteristics of a preson that either enhance or decrease the possibilities of mental health problems (Rolf, Masten, Cichetti, Nuecht-

\footnotetext{
The analysis of the data was supported by an initiatory grant from the Research Office of Wilfrid Laurier Univetsity. The action component of the project described in this paper is supported by Multiculturaliem Canada. For their collaboration in the design and/or conduct of this study, 1 wish to thank the following Community members: Reyna Andrino, Josefa Gonzalez, Herberth Hernandez, Pablo Hemandez, Elsa Pricto, and Daisy Ramirez. I also wish to thank all the community members who participated in this research. 1 received very competent research assistance from Charity Akotia, Richard Janzen, and Colecen Wiltshire, Thank you all Correspondence concerning this article should be addressed to Isaac Prilleltensky, Deparunent of Psychology, Wilfrid Laurier University, Waterloo, ON N2L 3CS.
} 
erlein, \& Weintraub, 1990). In the case of immigrant children, Eisikovits and Beck

(1990) contend that "the few empirical studies available address the issue of educational achievement, generally concentrating on impediments and blaming them on some negative predisposition of the immigrant group in question" (p. 177). The present contribution tries to balance that tendency by exploring both risk and pro-
tective factors involved in the adaptation of immigrants and refugees. Further, it is
in line with the call made by Munroe-Blum and her colleagues to "identify to in line with the call made by Munroe-Blum and her colleagues to "identify the protective forces at play in immigrant families" (Munroe-Blum, Boyle, Offord, \&

\section{LITERATURE REVIEW}

This review will focus primarily on the adaptation of immigrant children. As there is substantially more information available on the adjustment of immigran
adults, only a brief coverage of this group will be presented.

It should be pointed out that as the literature on immigrant children is not very rich, I resorted to looking at adaptation processes of minority children as well. While both groups are far from equivalent, there are sufficient similarities to permit us to fill some of the gaps existing in the immigrant children literature with rethe family, school, and community will be respectively reviewed.

\section{Family Risk Factors}

At the family level, children are adversely affected by an increase in stressful life events experienced by their parents. The general migratory or acculturative stress suffered by the parents has potential negative repercussions for every member of the family. Prominent among these acculturative stressors are inadequate housing and the struggle to accommodate to new cultural norms and daily routines (Aronowitz, 1984; Berry, 1988; Carlin, 1986; Miller. O'Neal, \& Scott, 1982; Munroe-Blum et al, , 1989). "In Canada, negative public attitudes, separation from family and community, inability to speak English or French, and failure to find suitable employment are among the most powerful predictors of emotional distress children migrants" (Beiser et al., 1988, p. i). Due to these and other difficulties, involvement (Koplow \& Ment serious problems with limited parental constructive "the physical and mental health of 1990; O'Neal, 1982). As Carlin (1986) put it, child's future adjustment" (p. 137)

Acculturation places heavy

and marital discord resulting from demands on the entire family structure. Family (Burke, 1980; Sluzki, 1979). Comflets increased levels of stress are not uncommon casioned by "differential rates of aljicts in values between children and parents, oc4), further exacerbate family tension. Climent to the new culture" (Baptiste, 1990, p. faster, and their newly acquired values soldren and adolescents tend to acculturate held by their parents. Youngsters wish to sometimes clash with the traditional ones order to feel accepted (Miller, Chamber, rapidly adopt North American customs in trast, do not wish to relinquish their traditionan, 1981). Their parents, in con- 
(Baptiste, 1990: Koplow \& Messinger, 1990; Wakil, Siddique, \& Wakil, 1981; Westermeyer, 1989; Williams, 1989).

Role redefinition and role reversals occur in many immigrant families. This constitutes a risk because children need to assume roles for which they may not be developmentally prepared (Eisikovits \& Beck, 1990; Westermeyer, 1989). Children find themselves translating for their parents in encounters with professionals, helping in the business, and negotiating situations with community agencies and helpers. Further restructuring occurs in the marital dyad where either mother or father assume a new position as wage earner or homemaker, frequently causing friction between them (Grant, 1983). While these accommodations are not necessarily pernicious, they do exact, at least temporarily, a toll on the family.

Lack of family support is another factor placing the newly arrived Canadians in a vulnerable situation. All the while the family is contending with the stressful life events stated above, it is doing so without family support which, in some countries of origin, tended to be very strong (Baca, Bryan, McLean-Bardwell, \& Gomez, 1989; Beiser et al., 1988; Giles, 1989). This hardship is especially felt by immigrant women, who by virtue of the barriers encountered in finding suitable employment or language training, tend to stay home and experience great degrees of isolation (Arnopoulos, 1979). As Estable (1986) pointed out,

\begin{abstract}
Women who do not speak English or French also experience considerable isolation in their daily lives. .... In the long term, many immigrant women even become isolated from their own families, as husbands and children become fluent in the workplace and at school. This adds to immigrant women's daily load of stress, and further places them in a dependent position in relation to the rest of their family (p. 43).
\end{abstract}

\title{
Family Protective Factors
}

A few factors counteracting the potential for negative outcomes can be identified. An integrative mode of acculturation whereby parents and children begin to embrace the new culture without undermining their own is an important protective factor (Berry, 1988; Grant, 1983; Harrison, Wilson, Pine, Chan, \& Buriel, 1990; Williams \& Berry, 1991). Conflicts between children and parents are prevented when the latter realize the need of the former to belong in the new society. Hence, parental acceptance of children's endorsement of host-country values is an important preventive measure (Wakil et al., 1981). The importance of support from extended family and the ethnic community cannot be underestimated (Grant, 1983; Harrison et al., 1990; Jenkins, 1983; Williams \& Berry, 1991). Networking with family members and individuals who are experiencing similar difficulties can buffer acculturative stress.

\section{School Risk Factors}

At school, immigrant children face two very demanding tasks: (a) coping successfully academically, and (b) establishing new friendships, Risk factors associated with these challenges may result in either early drop-out or damage to selfesteem. Successful social and academic adaptation is mediated by the ability to master the new language, a process that may take a long time and is not always handled efficiently (Baca et al., 1989; Cummins, 1986a; Forton, 1989). 
Research has shown that assessment procedures in schools tend to discriminate against foreign-born children (Cummins, 1986b, 1987; Hilliard, 1979). As a result, immigrant students are inappropriately placed in special education programs meant for children with learning disabilities (Duran, 1990). Educational problems are exacerbated by the lack of communication between teachers and parents ( $\mathrm{Cum}_{\mathrm{H}}$ mins, 1986a; Giles, 1989). Exclusionary institutional practices obstruct meaningful parental participation in the schooling of their children, thus reducing their educa-

But perhaps the most powerful force working against immigrant children in schools is prejudice and racism. Though they do not always manifest themselves overtly, their presence in many schools cannot be questioned (Aronowitz, 1984; Beiser et al, 1988; Giles, 1989; Skutnabb-Kangas \& Cummins, 1988).

In addition to these educational impediments, it should be remembered that some immigrant students have had little or no formal schooling, while others have had a very disrupted academic history (Duran, 1990). With so them, immigrant children must have proper supports in place. To these we now

\section{School Protective Factors}

Several protective factors may be identified at the school level. English as a Second Language programs are a necessity (Aronowitz, 1984; Olsen \& Dowell, 1989). But over and above transmission of the language, a multicultural orientation on the part of teachers that encourages ethnic pride and is welcoming of new students and their parents is a must (Baca et al, 1989; Cummins, 1986a; Eisikovits \& Beck, 1990; Giles, 1989; Hilliard, 1979; Jack, 1987/1988; Spencer \& MarkstromAdams, 1990; Westermeyer, 1989; Williams, 1989).

Finally, support from peers of the same ethnic background (Howes \& Wu, 1990) and from local children (Eisikovits \& Beck, 1990) greatly expedites adaptation. They help with homework, introduce them to new friends, and in some

\section{Community Risk Factors}

There is similarity between the dynamics of adaptation in school and community. The same racial prejudice experienced in educational settings is felt in the community at large (Beiser, 1990; Spencer \& Markstrom-Adams, 1990). Acculturative stress in the form of social isolation (Dyal \& Dyal, 1981), restricted access to services, daily hassles (Kuo \& Tsai, 1986; Miller et al., 1981; Ng, 1988; Westermeyer, 1989), and economic deprivation (Moyerman \& Forman, 1992; MunroeBlum et al. 1989) add to the challenge of resettlement.

The disadvantages faced by some immigrant women, who constitute a distinct vulnerable group, deserve special mention. "The immigrant woman is often a shadow figure in the Canadian mosaic, frequently sacrificing her own development so that her husband and children may be more fully integrated into Canadian society" (Multiculturalism Canada, 1984, p. 3). When immigrant women manage to join the
labour force, they experience tremendous hardships. 
Due to the nature of their paid employment (e.g., part-time, seasonal, or piece work), labour standard legislation is not rigidly enforced in many cases, which further exacerbates the poor conditions of their work. Meanwhile, their domestic responsibilities, including childcare, and lack of educational opportunities mean that their mobility in the wage labour market is severely curtailed. As a result, most non-English speaking immigrant women, if they enter the labour force, become members of the most exploited sectors of the working population (Ng, 1988, p. 17).

\section{Community Protective Factors}

Living in a neighbourhood where there is a concentration of people from similar backgrounds, or just having social support from members of the same ethnic community have been found to be mitigating forces against stress (Dyal \& Dya1, 1981; Kuo \& Tsai, 1986; Moyerman \& Forman, 1992; Williams \& Berry, 1991). Sufficient information and orientation about the new country and its services is also very helpful (Spencer \& Markstrom-Adams, 1990).

As far as the adults are concerned, creating tolerant attitudes toward new Canadians, providing help with resettlement, facilitating social support, training in official languages, and opportunities for employment have been recognized by the Canadian task force as protective factors of preeminent importance (Beiser et al., 1988; Canadian Task Force on Mental Health Issues Affecting Immigrants and Refugees, 1988).

In conclusion, it should be emphasized that while the process of moving to a new country and culture does entail considerable stress, adverse mental health outcomes are not inevitable (Beiser et al., 1988; Moyerman \& Forman, 1992; Munroe-Blum et al., 1989). The immigration experience may be conceptualized as a period of enhanced vulnerability where the person is more susceptible to risk factors.

\section{PURPOSE AND SOCIAL CONTEXT OF RESEARCH}

With very few exceptions (Alcalde, 1992; Klejner, 1992; Neuwirth, 1989; Sehl \& Naidoo, 1985), the literature does not have much to offer on the immigration experience of people from South and Central America in Canada. Concerning the second objective of this paper, namely to describe a community-driven study, there are a few features that distinguish this project from most others reported in academic publications. Following the values of empowerment advanced by Prilleltensky (in press), this action research attempted to give a voice to the participants, to include them in the design and conduct of the study, and to promote their political aspirations by translating a needs assessment into a social action project. Other principles enacted in this work are congruent with the guidelines put forth by Williams and Berry (1991) for primary prevention interventions among refugees and immigrants. They argue that

Lessons from anthropology and cross-cultural psychology tell us about the importance of time spent in the field. In any cross-cultural work, psychologists have to fight against the tendency toward professional distancing by leaving their offices and clinics and spending time with refugees in their environment (p. 639). 
The report that follows is based not only on the formal interviews and focus groups conducted but also on many hours visiting with members of the community and organizing activities. Williams and Berry (1991) further make the point that for those interested in prevention, "active collaboration with members of the ethnic community is a requirement for such an approach. If this perspective is not taken, psychologists will add the further risks of ethnocentrism and victim-blaming to those already being experienced" (p. 640). This work is an example of collaboration between the researcher and community members in trying to develop it neighbourhood association. Being from Latin America myself helped a great deal in establishing a collaborative relationship with the immigrant group.

The group is composed of families which entered the country under the ref ugee immigration class. They have all been granted lawful entry into Canada because of humanitarian reasons. 1 It is important to clarify that when referring to the participants of the research, the word refugees denotes the immigration class under which they entered the country. Furthermore, it is used as a reminder that these families have had to endure significant hardships prior to their arrival in Canada. Some of our families experienced repeated dislocation, persecution, and witnessed extreme violence, including the killing of family members. Persons coming to Canada in other immigration classes are less likely to have suffered as much before migration. The use of the word "refugee," however, does not exclude the use of the term "immigrant," Having been granted permission to live in Canada, these refugees are now immigrants in our country.

The group originated at the initiative of the author, who invited a few Latin Americans residing in the same co-operative housing complex to discuss the needs of their children. In order to explore this issue further, the group decided to undertake a needs assessment involving all the 19 Spanish-speaking families living in the complex. The research team, facililtated by myself, provided input into the topics tions regarding the research process itself.

Consensus was attained pertaining to the main goal of the study: It was to examine the perceived risk and protective factors involved in the adaptation of immigrant children and adults with a view toward transforming their voices into a
project to ameliorate stress and improve coping.

\section{CONCEPTUAL FRAMEWORK}

In order to adhere to the guiding principles stated above, a model was developed whereby (a) researcher and participants could collaborate, (b) the unique experience of this group of immigrants and refugees could be heard and compared with the literature on the topic, and (c) research could be translated into action.

The framework, schematically depicted in Table 1 , represents a mode of thinking that combines the knowledge accumulated so far on the topic with input from participants in a way that leads to program development. Three contexts for study and intervention were identified in this project: (a) family, (b) school (in the case of children) or major occupation (in the case of adults), and (c) community. The process of understanding and improving life in each of these spheres begins with asking participants for a descriptive statement of their experience in each set- 
TABLE 1

Conceptual Framework for Research and Action on Communal Well-Being

\begin{tabular}{|c|c|c|c|c|c|}
\hline \multirow{2}{*}{$\begin{array}{l}\text { Context of } \\
\text { Study and } \\
\text { Intervention }\end{array}$} & \multicolumn{4}{|c|}{ Research and Action Process } & \multirow[b]{2}{*}{ Action } \\
\hline & $\begin{array}{l}\text { Description of } \\
\text { Situation }\end{array}$ & $\begin{array}{l}\text { Risk } \\
\text { Factors }\end{array}$ & $\begin{array}{l}\text { Protective } \\
\text { Factors }\end{array}$ & Recommendations & \\
\hline Family & $\begin{array}{l}\text { Participants' } \\
\text { input }\end{array}$ & \multicolumn{3}{|c|}{$\begin{array}{l}\text { Participants' input and literature } \\
\text { review. }\end{array}$} & $\begin{array}{l}\text { Participants } \\
\text { output }\end{array}$ \\
\hline $\begin{array}{l}\text { School or } \\
\text { Major } \\
\text { Occupation }\end{array}$ & $\begin{array}{l}\text { Participants } \\
\text { input }\end{array}$ & \multicolumn{3}{|c|}{$\begin{array}{l}\text { Participants' input and literature } \\
\text { review }\end{array}$} & $\begin{array}{l}\text { Participants } \\
\text { output }\end{array}$ \\
\hline Community & $\begin{array}{l}\text { Participants" } \\
\text { input }\end{array}$ & \multicolumn{3}{|c|}{$\begin{array}{l}\text { Participants' input and literature } \\
\text { review }\end{array}$} & $\begin{array}{l}\text { Participants' } \\
\text { output }\end{array}$ \\
\hline
\end{tabular}

ting. The next step is to obtain their opinions regarding perceived risk and protective factors. This is done after a description is requested in order to avoid prematurely colouring their observations with positive or negative questions. The first stage is aimed at obtaining the unique and particular vicissitudes of this group. The second stage allows for comparison and integration of the material provided with the existing literature. The third step, linking research and action, is devoted to the formulations of recommendations on how to ameliorate stress and improve coping. The final phase requires output from both participants and investigator to enact the suggestions made.

\section{METHODOLOGY}

In order to meet the goal of this study an interview guide was developed based on the framework presented above. Parents were asked to contribute their opinions on their own experiences as well as on that of their children. In-depth interviews were conducted with 10 adults (five women and five men) and 8 children (five boys and three girls) from three different countries: El Salvador, Guatemala, and Nicaragua. Their length of stay in the country ranged from five months to six years. The adults were 22 to 42 years of age. The children's ages ranged from 8 to 17 years old. The interviews with adults lasted approximately 90 minutes. Interviews with children lasted about 25 minutes. In many cases interviewers visited the family twice to complete the interviews.

Two focus groups were held. These had the dual purpose of involving the community in the needs assessment, and expanding on the information received in the interviews. Focus groups were attended by adults only. The first one was attended by nine persons and the second one by ten. The second focus group. which served also as a community feedback session, helped verify the issues identified during the individual interviews. The entire research project was conducted in Spanish. 


\section{FINDINGS AND DISCUSSION}

Standard procedures of qualitative analysis were utilized in interpreting the da. ta from the interviews and focus groups (Guba \& Lincoln, 1989; Lord, Schnarr, \& Hutchison, 1987; Patton, 1987, 1990; Strauss \& Corbin, 1990). Findings pertaining to both adults and children will be reported in each section. An overview of the major risk and protective factors identified in the literature and in this investigation can be found in Table 2. As can be seen, this investigation replicated findings obtained in previous reports. The factors placed under the "Findings of Present Research" column denote those that were either unique to this research (such as some protective family dynamics), or that have been forcefully expressed by our participants (such as lack of proper orientation and feelings of marginalization at school). Important factors reported only under the "Literature Review" column mean that comparable findings were not observed in the present study. Finally, factors reported across the two columns mean that they were found both in the literature and in the present investigation.

\section{Risk and Protective Factors in the Family}

Both parents and youngsters reported that in general the move had a salutary effect for the children who had an easier time than their elders in adapting to Canada. With the exception of role reversal for children, all the family risk factors described in the literature review were mentioned by the participants.

Concerning the lack of support associated with separation from extended family, children reported missing meaningful others such as grandparents, uncles, and cousins with whom they would spend quality time and from whom they would seek advice in moments of need. Lack of support from extended family and friends was the most frequently reported risk category by adults.

A clash between the newly acquired western values of the children and the traditional ones of their parents was a source of concern for both adults and youngsters. Related to that was friction created by what parents perceived was a lack of parental respect inherent in this more "liberal" culture. Migratory stress engendered by the encounter with unfamiliar customs was also identified.

Friction in the house was also found to be associated with an unfair distribution of jobs. Mothers commented that either due to their husbands' shift work, or because of lack of hired help, to which some of them were accustomed in Latin America, their domestic duties have increased noticeably. Consequently, there is a heavy burden on some mothers, particularly on single mothers. A single mother of three commented:

It has been very difficult to juggle all my responsibilities at home and at school. At school, I constantly find myself thinking about my kids. At home, I have so many things to do that I can't keep up with school work.

Women in particular have indicated that the new schedules of work and/or school limit the time they spend with their children. Most of them were used to spending more time with their children. In two-parent families, most of the "balancing act" of keeping the house in order, preparing meals, and looking after the children was assumed by the women. 
TABLE 2

Overview of Major Risk and Protective Factors in Adaptation of Immigrants and Refugees

Risk Factors

Protective Factors

\begin{tabular}{clll}
\cline { 2 - 4 } Context Literature Review & $\begin{array}{l}\text { Findings of } \\
\text { Present } \\
\text { Research }\end{array}$ & Literature Review & $\begin{array}{l}\text { Findings of } \\
\text { Present } \\
\text { Research }\end{array}$
\end{tabular}

Parents suffer acculturative stress due to: unemployment, negative public attitudes, language, lack of support from family and community, new culture. Stress affects entire family.

Family Family and marital discord, valuesconflicts between children and adults.

Role re-definition and role reversal.
Integrative mode of acculturation.

Positive reframing,

Family cohesion.

Parental acceptance of children's new values. Open dialogue regarding stressors.

Moral and material support from family. extended family, and ethric community.

Inappropriate assessment and placement.

Problems with language acquisition.

Non-inclusive policies and negative attitudes toward newcomers.

Lack of home-school communication.

School

Lack of
proper
orientation.
Inability of
parents to
help due to
language.
Feelings of
marginali-
zation.

Prejudice, discrimination, and social isolation experienced primarily by adults.

lack of proper orientation and restricted access to services. Economic hardships.

Community
Adolescents' struggle with cultural identity.
Proper ESL training

Teachers' integrative and multicultural orientation.

Efforts by school to reach out to parents.

Support from Canadian and same-ethnic group peers with school work and social integration.

Remedial help from teachers or family members.

Residing in community with sameethnic group members.

Sufticient information and orientation about new country.

Moral and material support from family, friends, church, agencies, and self-help groups.

Positive reframing of immigration ex- 


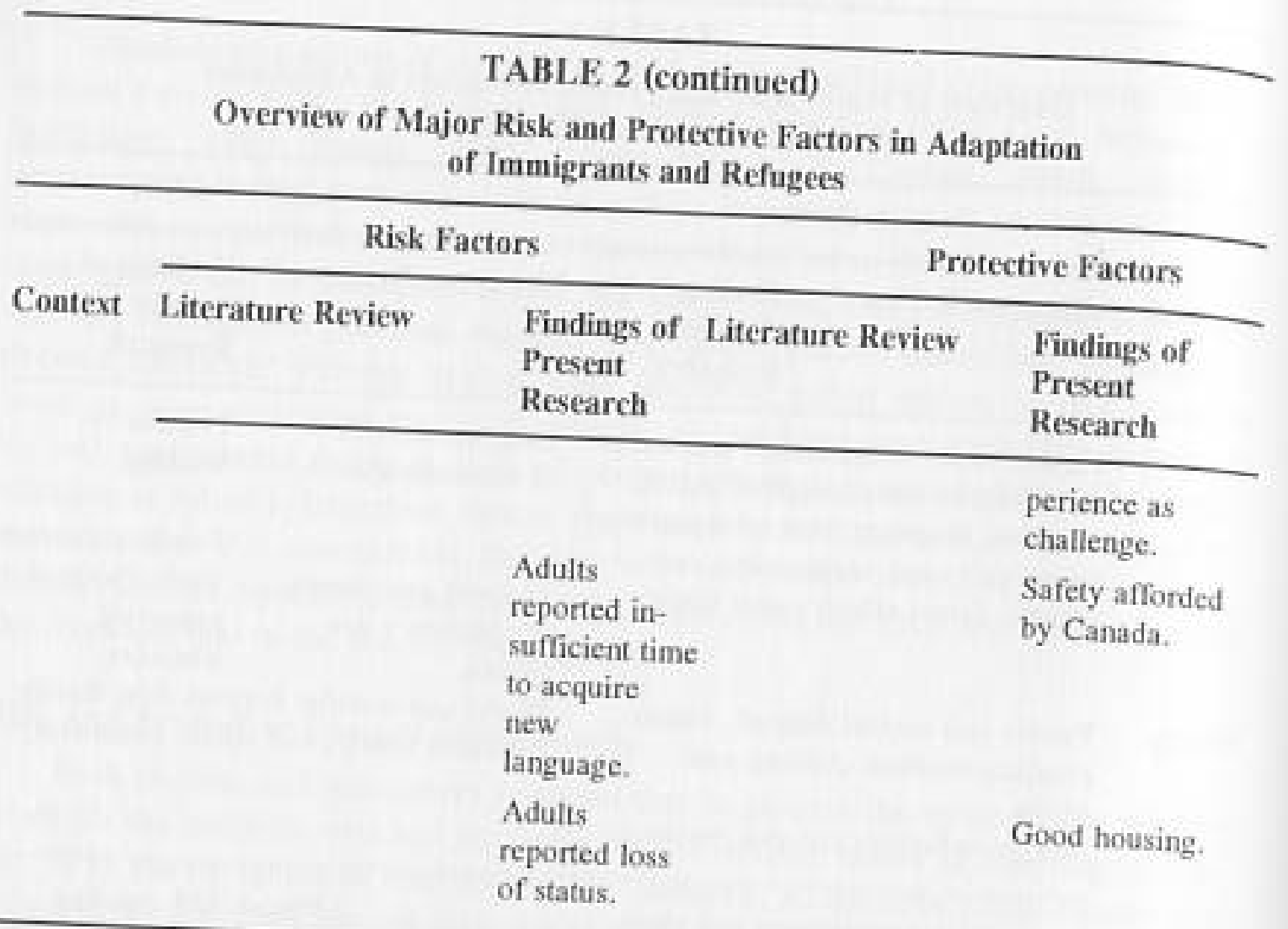

Protective factors identified in this research begin to answer the call made by Munroe-Blum and colleagues "to identify the 'protective' forces at play in immigrant families where social hardship is experienced with no increase in child morbidity" (1989, p. 519). Indecd, certain families in this research exhibited remarkable degrees of resilience in the face of adversity and displayed a great deal protective factor reported by participants that appeared previously in the literature, Insight into how some immigrant families "protect" their children was obtained from the following mechanisms. Perhaps the most important coping strategy was a reframing of the migratory experience in positive terms. Obstacles were viewed as temporary and minor in comparison to the long-term benefits to be accrued from living in a safe and prosperous country. For example, adolescents reported having been told by parents that their educational options would be much enhanced in Canada. Similarly, having arrived from countries where violence was rampant, participants appreciated the sense of safety Canada afforded them. Barriers to adjustment were seen in some instances as a small price to pay to provide children
with a safe environment.

A supportive family atmosphere was also deemed highly protective. Open dialogue among parents (mothers in particular) and children, concrete help with house chores, and recreation with the entire family contributed to a climate of co-

Without romanticizing the immigration experience of refugees, I would conjecture that having overcome crises and tragic events together has given these families a renewed appreciation for life that brings them together. Of course not all families react the same way, but a few of the ones we interviewed definitely gave 
that sense. Indeed, some families of our sample are examples of balanced, wellconnected, and adaptable units (Olson, Russell, \& Sprenkle, 1983), "able to use existing resources and define the situation so as to resist systemic change and maintain stability" (McCubbin \& Patterson, 1983, p. 10). Compared to what some of these families experienced in their countries of origin, acculturative stress is minor and may be reframed as a challenge more than perceived as a debilitating force. Another single mother acknowledged that her present retraining in "carpentry, hairstyling, and food service is physically very demanding . . . but," she added, "I realize that I'm capable of learning something new every day."

\section{Risk and Protective Factors at School}

Children and parents alike reported this to be the most problematic area for the young immigrants. Previously reported risk factors that were confirmed in this investigation included lack of English proficiency, prejudice and discrimination, minimal communication between school and home, and misdiagnosis of abilities. The last two were vividly reported by a mother who did not know of her child's difficulties until the end of the school year when she was told that her child could not be promoted. Yet, whenever she inquired about his situation throughout the academic year she was told, in a somewhat paternalistic fashion, that everything was fine. The child was then moved to another school where he progressed at a satisfactory pace. An either exclusionary or paternalistic mode of communication was experienced by many immigrant parents in their encounters with school officials. As a result, some of the adults developed a suspicious attitude toward school in general. This is congruent with the literature on the subject (Cummins, 1986a, 1988; Giles, 1989).

Both parents and students expressed a concern regarding the lack of proper orientation to the school system. Students in primary and secondary grades had little or no introduction to the institution and its procedures prior to entrance. Many felt "lost" in the new place and that caused considerable confusion.

Related to prejudice and discrimination, the presence of intergroup conflict and feclings of marginalization at school were mentioned. Most of all, children wanted to be perceived as "normal," but they encountered several barriers. A child shared his feelings of being different when he disturbingly told his mother that he was "the only one in his class who didn't have blue eyes." While this concern may not have been precipitated by an act of teachers or peers, it does signify the internal pressure kids feel to "be the same."

An interesting protective dynamic was revealed by an adolescent who argued that "friends from the same cultural background are very helpful at first, but then it is important to become acquainted with Canadian youth." This way, in his opinion, one could rely on Spanish friends during the most difficult first few months, but then one should move on and try to incorporate into the Canadian group.

The importance of a multicultural orientation in the school cannot be underestimated. A child experiencing considerable learning problems in one school flourished in another where staff showed a much more tolerant attitude toward newcomers. 


\section{Risk and Protective Factors in the Community}

It should be noted that the risk factors at this level were reported primarily by parents. Children did not recognize their community as a problematic setting for their adaptation. Chances are they did not experience the discrimination or prejudice found in the literature because the community where they live is inhabited mostly by immigrants. In addition, as opposed to school, they had more choice in the selection of peers they interacted with, thereby increasing the chances they opted to associate with "friendlier" youngsters. These hypotheses are supported by some adult participants and by work indicative of the protective aspects of residing in a place where there is a high proportion of families from the same background (Dyal \& Dyal, 1981; Kuo \& Tsai, 1986).

As was the case with the school setting, children wished to be perceived as "normal" and wanted to "fit in." They struggled at first with their cultural identity. This was particularly true for adolescents who have already developed sources of identification in their countries of origin. Parents observed that the "liberal" ways of Canadian society put their children at risk for substance abuse and other "undesired behaviours" such as staying out late, associating with a "bad crowd," driving at an early age, and the like. Parents also recognized that financial restraints restricted their children's mobility and opportunities for recreation.

In general, and in contrast to their children, parents seem to be having a difficult time adjusting. The most frequently reported concern with the adaptation process was the lack of English proficiency. Adults repeatedly showed dissatisfaction with the limited amount of time they have to study the new language. Mastering the language, participants noted, significantly expedited the adaptation process and opened doors for employment and education.

Unemployment or underemployment ranked second in the order of risk factors. This is related to a serious assault on the immigrant's self-esteem: the loss of social status. Several professionals interviewed in this and other research (Alcalde, 1992) could not resume in Canada their chosen occupations due to severe restrictions or unrecognized credentials (Estable, 1986).

A special form of occupational discrimination was perceived by a father who contended that immigrants are "streamed into low-paying jobs and discouraged to pursue educational goals." This was based on contacts he had with educational, social, and employment agencies. In general, many of these men and women experience the double stressor of being immigrants and poor. Their low-class position brings with it financial and psychological hardships that add to the already high levels of acculturative stress.

Children and parents concurred in their assessment of the protective elements in the community. These were the assistance received from friends and members of their own community on a variety of issues, good housing, and the fact that Canada is a safer place than their nations of birth. Aid from various sources featured prominently as a protective factor. Help received from agencies (ESL personnel, self-help groups), from people in similar situations, and from church was very much appreciated. In the case of one family, the spiritual solidarity and material contributions offered them by a local church was nothing less than a "life saver." 


\section{ACTION}

Based on the research and recommendations made by participants, the literature, and discussions held by the core organizing group, an action plan was formulated. Its two leading goals were to: (a) reduce the stressors associated with immigration, and (b) facilitate the adaptation and integration of all family members. Three specific objectives were proposed by the organizing committee:

1. Enhance educational opportunities of children by improving communication with school and creating self-help activities initiated by parents.

2. Reduce acculturative stress through the preservation of ethnic values and acquisition of essential orienting information to Canadian customs, laws, and language.

3. Foster a sense of community and social support through the organization of community events and the development of formal and informal networks.

With help from Multiculturalism Canada, the group has begun working on these objectives. Priorities have been established by the community and psychologist trained in South America has been hired to coordinate the project. Initially we intend to focus on the Latin American families situated in the cooperative housing and immediate surroundings. There are about 35 Latin American families in this area. Following this period of cohesion building, we expect to be able to reach out to other members of the regional Spanish community as well as to other immigrant groups.

\section{CONCLUSION}

The study reported in this paper is a first step in a project designed to empower members of a community to identify their needs and assert their rights. The research served not only as a basis for specific action but also as a catalyst for community development and mobilization. An important secondary effect of this work has been the creation of informal helping networks among the residents of the co-operative, contributing toward a psychological sense of community. Another meaningful ramification has been the nurturance and emergence of community leaders.

While the content identified in this research may not necessarily be transferable to other populations, possibly not even to other Latin American groups, the process utilized in this context can be attempted at other settings. The small sample employed in this research and the unique co-op housing situation place limitations on the generalizability of the work. Nevertheless, there is no reason why an empowerment agenda, similar to the one successfully implemented in this case, could not be adopted in other communities.

\section{NOTES}

1. Under the Immigration Act, people may enter Canada in one of three categories: independent immigrants, family class, or Convention refugees. While Canada adopts the United Nations' definition of refugees, at times individuals who are not covered by this definition are granted permission to come here for humanitarian reasons. In this study, the word refugees denotes primarily the background for migrating. Since they have all 
gained lawful entry into the country and reside here on a permanent basis, they can atso
be regarded as immigrants.

\section{RÉSUMÉ}

Cet article contient deux objectifs. Premièrement, celui de contribuer à 1 ta compréhension des facteurs de risque et de protection reliés à l'adaptation des immigrants et des réfugiés. Deuxièmement, de rendre compte d'un projet de recherche-action fondée sur la participation et l'implication première de la communauté. Ces deux objectifs sont intégrés dans un cadre conceptuel reliant des connaissances générales sur le thème et les expériences uniques d'un groupe de réfugiés, ayant comme visée de conduire à l'action. L'étude débute d'abord en relevant trois faiblesses dans la littérature scientifique: (a) le manque de recherches sur l'adaptation des enfants d'immigrants et de réfugiés, (b) le besoin d'étudier les mécanismes de protection chez les familles de réfugiés, et (c) la pauvreté des liens établis entre recherche et pratique.

\section{REFERENCES}

Alcalde, J. (1992). Working toward health: A needs assessment project with the Vietnamese, Hispanic, and Polish communities in Kitchener-Waterloo. An unpublished report of the
Multicultural Health Coalition, Waterloo Region.

Arnopoulos, S.M. (1979). Problems of immigrant women in the Canadian labour force. Ottawa: Advisory Council on the Status of Women.

Aronowitz, M. (1984). The social and emotional adjustment of immigrant childnent of the literature. Intemational Migration Review, 18(2), 237-252

Baca, R., Bryan, D. Mclean-Bardwent, C. \& Gom,

the port-of-entry

Baptiste, D.A. (1990). The Irtemational Migration Review, 23(1), 3-23.

Issues and recomm

Beiser, M. (1990, April).

in resenlement countries. new challenge for wres. Paper presented at Symposium on children and migration: A

Beiser, M. Barwick, C., Berlde social services, Hong Kong.

Milne, W., Naidoo., Berry, J.W., da Costa, G., Fantino, A.M., Ganesan, S., Lee, C., has been opened: Mental heath , Tousignant, M., \& Vela, E. (1988). After the door Ministry of Multliculturatis health issues aflecting immigrants and refugees. Ottawa:

Berry, J.W. (1988). Acculturation and psychip, and Health and Welfare Canada.

J.W. Berry \& R.C. Annis and psychological adaptation: A conceptual overview. In immigrants, refugees, native peoples, Eithic psychology: Research and practice with Amsterdam: Swets \& Zeillinger.

Burke. A.W. (1980), Family stess.

stress and the precipitation of psychiatric disorder. Intemational

Canadian of Social Psychiatry, 26(1), 35-40.

Revine of Force on Mental Health Issues Affecting Immigrants and Refugees. (1988) and Citiz mitherature on migrant mental health. Ottawa: Ministry of Multiculturalism

Carlin, J.E. (1986), and Health and Welfare Canada.

C.I Will 986). Child and adolescent refugees: Psychiatric assessment and treatment. It (pp 131-139). Westermeyer (Eds.), Refugee mental health in resentement countries

Cumuning, Wemisphere,

. (1986a). Empowering minority students; A framework for intervention.

ind Educational Review, 56, 18-36.

focus, out of focus, out of control? Joumal of Reading. Writing, and Leaming Disabilities, 2(1), 9-19. 


\section{THE IMMIGRATION EXPERIENCE OF LATIN AMERICAN FAMIIIES}

Cummins, J. (1987). A theoretical framework for bilingual special education. Exceptional Children, S6(2), 111-119.

Cummins, J. (1988). From multicultural to anti-racist education: An analysis of programmes and policies in Ontario. In T. Skutnabb-Kangas \& J. Cummins (Eds.), Minority education: From shame to struggle (pp. 127-157). Philadelphia; Multilingual Matters.

Duran, M. (1990). Some thoughts concerning the education of refugee children. Refugee, $10(2), 10-13$.

Dyal, J.A., \& Dyal, R.Y. (1981). Acculturation, stress, and coping: Some implications for research and education. Intemational Joumal of Intercultural Relations, 5, 301-328.

Eisikovits, R.A., \& Beck, R.H. (1990). Models goveming the education of new immigrant children in Israel. Comparative Education Review, 34(2), 177-195.

Estable, A. (1986). Immigrant women in Canada: Current issues. Otrawa: Canadian Advisory Council on the Status of Women.

Forton, J. (1989). Realizing the dream: A bibliographic essay. Realizing the dream: Selected conference proceedings. (ERIC Document Reproduction Service No. ED 314 960.)

Giles, H.C. (1989). Counseling Haitian students and their families: Issues and interventions. Joumal of Counseling and Development, 68(3), 317-320.

Grant, G. (1983). Impact of immigration on the family and children. Joumal of Children in Comemporary Society, 15(3), 27-37.

Guba, E.G., \& Lincoln, Y.S. (1989). Fourth generation evaluation. London: Sage.

Harrison, A.O., Wilson, M.N., Pine, C.J., Chan, S.Q., \& Buriel, R. (1990). Family ecologies of ethnic minority children. Child Development, 61, 347-362.

Hilliard, A.G. (1979). Cultural diversity and special education. Exceptional Children, 46 , 584-588.

Howes, C., \& Wu, F, (1990), Peer interactions and friendships in an ethrically diverse school setting. Child Development, 61, 537-541.

Jack, D. (1987/1988). Improving students' ethnic attitudes: A grade 3 multicultural education program. Multiculturalism, $11 / 12,14-16$.

Jenkins, S. (1983), Children who are newcomers: Social service needs. Joumal of Children in Contemporany Sociery, 15(3), 39-47,

Klejner. B.A. (1992, June). Immigration settlement: An ethnopsychological study. Paper presented at the Annual Convention of the Canadian Psychological Association, Quebec City, Quebec.

Koplow, L., \& Messinger, E. (1990). Development dilemmas of young children of immigrant parents. Child and Adolescent Social Work Joumal, 7(2), 121-134.

Kuo, W.H., \& Tsai, Y. (1986). Social networking, hardiness and immigrant's mental health. Joumal of Health and Social Behaviour, 27(2), 133-149.

Lord, J., Schnarr, A., \& Hutchison, P. (1987). The voice of the people: Qualitative research and the needs of consumers. Canadian Joumal of Community Mental Health, 6(2), 2536.

McCubbin, H.1., \& Patterson, J.M. (1983). The family stress process: The double ABCX model of adjustment and adaptation. Marriage and Family Review, 6, 7-37.

Miller, B., Chamber. E., \& Coleman, C. (1981), Indo-Chinese refugees: A national mental health needs assessment. Migration Today, 9(2), 26-31.

Miller, S.O., O'Neal, G.W., \& Scott, C.A. (Eds.). (1982), Primary prevention approaches to the development of mental healht services for ethnic minorities: A challenge to social work education and practice. New York: Council on Social Work Education.

Moyerman, D.R., \& Forman, B.D. (1992). Acculturation and adjustment: A meta-analytic study. Hispanic Joumal of Behaviomal Sciences, 14(2), 163-200.

Multiculturalism Canda. (1984). A portrait of immigrant women. Ottawa: Author.

Munroe-Blum. H., Boyle, M.H., Offord, D.R., \& Kates, N. (1989). Immigrant children: Psychiatric disorder, school performance, and service utilization. American Journal of Onhopsychiain, 59(4), 510-519.

Neuwirth, G. (1989). The sentement of Salvadorean refugees in Onawa and Toronto. (15C report No. [M-072/11/89.) Ottawa: Ministry of Supply and Services. 

$\mathrm{Ng}, \mathrm{R}$. (1988), The politics of community services: Immigrant women, class and state.
Toronto: Garamond Press. Olsen, L., \& Dowell, C. (1989). Bridges: Promising programs for the education of im-
migrant children. Los Angeles; California Tomorrow. Olson, D.H., Russell, C.S., \& Sprenkle, D.H. (1983). Circumplex model of marital and
family systems: VI. Theoretical update. Family Process, 22, 69-83.

O'Neal, G.S. (1982). Mental health in ethnic minority communities: An overview. In S,O Miller, G.S. ONeal, \& C.A. Scott (Eds.), Primary prevention approaches to the development of mental healh senices for ethic minorities: A challenge to social work education and practice (pp. 1-20). New York: Council on Social Work Education.

Patton, M.Q. (1987). How to use qualitative methods in evaluation. London: Sage.

Patton, M.Q. (1990). Qualitative evaluation and research methods (2nd ed.). London: Sage. and possibilities, Canadian Psychology,

Rolf, J., Masten, A.S., Cicchetti, D., Nuechterlein, K.H., \& Weintraub, S. (Eds.). (1990). Risk and protective factors in the development of psychopathology. New York:
Cambridge University Press. Sehl, M., \& Naidoo, J.C. (1985). The adaptation of Salvadorean refugees in Canada.
Multiculturalism, 9(1), 25-28. Skutnabb-Kangas, T., \& Cummins, J. (Eds.). (1988). Minority education: From shame to
struggle. Philadelphia: Multilingual Matters.

Sluzki, C. E. (1979). Migration and family conflict. Family Process, 18(4), 379-390.

Spencer, M.B., \& Markstrom-Adams, C. (1990). Identity processes among racial and ethnic minority children in America. Child Development, 61(2), 290-310. Strauss, A., \& Corbin, J. (1990). Basics of qualitative research: Grounded theory
procedures and techniques. London: Sage.

Wakil, S.P., Siddique, C.M., \& Wakil, F.A. (1981). Between two cultures: A study in socialization of children of immigrants. Joumal of Marriage and the Family. 43(4), 929 -
940 .

Westermeyer, H. (1989). Menal health for refugees and other migrants: Social and preventive approaches. Springfield, IL: Charles C. Thomas.

Williams, C.L. (1989), Prevention programs for refugees: An interface for mental health and public health. Jounial of Primary Prevention, 10. 167-186.

Willliams, C.L., \& Berry, J.W. (1991). Primary prevention of acculturative stress among refugees: Application of psychological theory and practice. American Psychologist. 46 , 